June 1991

\title{
Psychiatric Manifestation of Vitamin B-12 Deficiency: An Update
}

\author{
David Metzler, M.S., M.D. \\ University of Kentucky, Lexington, Kentucky \\ William H. Miller, M.D. \\ University of Kentucky, Lexington, Kentucky \\ C. Stephen Edwards, M.D. \\ University of Kentucky, Lexington, Kentucky
}

Follow this and additional works at: https://jdc.jefferson.edu/jeffjpsychiatry

Part of the Psychiatry Commons

Let us know how access to this document benefits you

\section{Recommended Citation}

Metzler, M.S., M.D., David; Miller, M.D., William H.; and Edwards, M.D., C. Stephen (1991) "Psychiatric Manifestation of Vitamin B-12 Deficiency: An Update," Jefferson Journal of Psychiatry. Vol. 9 : Iss. 2 , Article 8.

DOI: https://doi.org/10.29046/JJP.009.2.005

Available at: https://jdc.jefferson.edu/jeffjpsychiatry/vol9/iss2/8

This Article is brought to you for free and open access by the Jefferson Digital Commons. The Jefferson Digital Commons is a service of Thomas Jefferson University's Center for Teaching and Learning (CTL). The Commons is a showcase for Jefferson books and journals, peer-reviewed scholarly publications, unique historical collections from the University archives, and teaching tools. The Jefferson Digital Commons allows researchers and interested readers anywhere in the world to learn about and keep up to date with Jefferson scholarship. This article has been accepted for inclusion in Jefferson Journal of Psychiatry by an authorized administrator of the Jefferson Digital Commons. For more information, please contact: JeffersonDigitalCommons@jefferson.edu. 


\title{
Psychiatric Manifestations of Vitamin B-12 Deficiency: An Update
}

\author{
David Metzler, M.S., M.D. \\ William H. Miller, M.D. \\ C. Stephen Edwards, M.D.
}

\begin{abstract}
Psychiatric manifestations of vitamin B-12 deficiency are reviewed from 1986 to the present. Specific clinical entities reviewed include depression, organic psychosis, obsessive-compulsive disorder, childhood manifestations and dementia. We recommend that consideration be given to B-12 deficiency as an etiological factor in some cases of depression, organic psychosis, certain childhood disorders and dementia. Routine screening of people over age 65 is addressed.
\end{abstract}

Vitamin B-12 (Cobalamin) deficiency may be as high as 5\% in populations over age 50 and up to $10 \%$ in patients over age 65 (1). The deficiency can result from inadequate intake (e.g., chronic unbalanced diet, breast-fed babies of vegan mothers), impaired absorption (e.g., gastric lesions, pernicious anemia, gastrectomy, small bowel disease), vitamin B-12 degradation (e.g., nitrous oxide anesthesia), increased requirement (e.g., pancreatic insufficiency, hyperthyroidism), or can be multifactorial (e.g., chronic alcoholism) (1-3). Since the first report of psychiatric sequelae by Addison in 1868 (4), a number of the manifestations of this deficiency have been recorded.

Hector and Burton reviewed the literature up to 1986 (5) and cited the following diagnoses, or symptoms, with an etiology of B-12 deficiency: 20 patients presented with delirium; 24 with depression; 14 with psychosis; 65 with slow cerebration, confusion, or memory loss; 4 with irritability or personality change; 15 with hallucinations or delusions; 4 with schizophrenia or paraphrenia; 3 with mania; and 3 with dementia. Recently, Lindenbaum et al (6) found a number of psychiatric manifestations of cobalamin deficiency in the 40 patients whom they studied. They found 15 patients who exhibited combinations of the following symptoms: 13 with memory loss; 3 with disorientation; 1 with obtundation; 2 with depression; 1 with irritability; 2 with hallucinations; 1 with agitation; 2 with marked personality change; and 1 with abnormal behavior.

The following discussion will review the recent literature of psychiatric sequelae associated with vitamin B-12 deficiency. The focus will be on the specific clinical entities of depression, organic psychosis, obsessive-compulsive disorder, childhood manifestations and dementia with respect to B-12 deficiency. 


\section{DEPRESSION}

In their letter to the editor, Levitt and Joffe (7) examined B-12 and folate levels in unmedicated patients with well-defined major depression to determine the association between psychotic depression and serum levels of B-12 and folate. Of 53 patients that they saw, five (9\%) had psychotic depression and 48 (91\%) had major depression alone. In those with psychotic depression, the authors found a statistically significant decrease for B-12 levels, but not for folate. They posed the question of whether or not lower B-12 predisposes to the development of psychotic symptoms during a depressive episode. In another study (8) of 44 consecutive unmedicated outpatients with a major depressive disorder, they noted a low B-12 level was associated with an early age of onset for major depression. Levitt and Joffe postulated that patients might be more susceptible to depression when B-12 deficiency begins at an early age.

Heap and Mumford (9) reported a case of what was thought to be post-partum depression, but was later discovered to be folate and B-12 deficiency caused by chronic giardiasis. The depressive symptoms were accompanied by malaise, lethargy, neglect at home, and visual hallucinations. The patient responded to the replacement of vitamin B-12 and folate.

\section{ORGANIC PSYCHOSIS}

Phillips and Kahaner (10) reported a patient with a paranoid psychosis without any change in cognition who presented with B-12 deficiency. This 89-year-old patient had become paranoid nine months prior to hospitalization and began to withdraw and stay at home. She was placed in a long-term care facility after having a "normal" organic work-up. The paranoia increased with symptoms of agitation, rapid speech, tangentiality, and a slightly elevated mood. The diagnosis was felt to be a delusional disorder or bipolar disorder, manic type, with psychotic features. Twelve months later after an acute myocardial infarction, her B-12 level was found to be low. After a few days of B-12 replacement therapy, a change was noted in her paranoia and shortly thereafter she resumed all her normal activities.

Lassen and Ewald (11) reported a 64-year-old woman who presented in a psychotic state with clouded consciousness, loss of orientation to person, place, and time, anxiety, restlessness, incoherent speech, and rapidly fluctuating delusions of persecution. Despite successful treatment of her hyperthyroidism the patient remained psychotic. Two weeks later, her serum B-12 level was found to be low. Replacement therapy was initiated and the psychosis disappeared.

\section{CHILDHOOD DISORDERS}

Garewal et al (12) studied 23 patients with infantile tremor syndrome. These patients all presented with tremors, pallor, skin pigmentation, regression of milestones, and a subnormal developmental quotient. These patients responded to B-12 
replacement therapy. Interestingly, the authors commented "the initial mental regression and persistence of mental retardation in children with infantile tremor syndrome could well be due to a deficient supply of vitamin B-12 to the nervous system during the crucial growing period." Sadowitz et al (13) described a case of a vitamin B-12 deficient infant who presented with decreased appetite, lethargy, irritability, listlessness, diminished ability to suck and swallow and loss of previously attained milestones. The patient responded within two days after B-12 replacement therapy was started. Cartlidge and Curnock (14) described a patient with Down's syndrome who had become lethargic, anorexic, irritable, and withdrawn. The patient also responded to vitamin B-12 therapy.

\section{OBSESSIVE-COMPULSIVE DISORDER}

In the only recent article reviewing B-12 level and obsessive-compulsive disorder (OCD), Hermesh et al (15) reviewed 30 patients. Six (20\%) of the 30 patients had abnormally low levels of vitamin B-12. This was statistically significant when compared to control groups. No replacement therapy was mentioned.

\section{DEMENTIA}

It is estimated that $10 \%$ of people over $65,20 \%$ over 75 , and $30 \%$ over 85 have some variety of dementia (16). Hector and Burton (5) focused on B-12 deficiency and its relation to the development of dementia. They found three cases of dementia which could be attributed to vitamin B-12 deficiency. They concluded that obtaining a vitamin B-12 level in searching for the etiology of dementia was unjustified.

Rawlinson and Eagles (17) studied 50 demented patients with diagnoses of Alzheimer-type dementia and multi-infarct dementia. They found no statistically significant differences in the two groups with respect to vitamin B-12 and folate levels. They divided the patients into those who lived with someone or those who lived alone. The group that lived alone had statistically significant lower B-12 levels. From this, they concluded, “. . . vitamin B-12 deficiency is much more likely to be a result, rather than a cause of dementing illness."

In other studies, Abalan and Delile (18) found low serum B-12 levels in four patients with pre-senile dementia, all of whom did not respond to replacement therapy. Karnaze and Carmel (19) found low B-12 levels in 29\% of their primary dementia patients and in none of their secondary dementia patients. They could not determine if the dementia caused the deficiency, if the deficiency caused the dementia, or if there was a common predisposition for the development of both disorders. Renvoize et al. (20) studied 150 demented patients and found 22 cases of vitamin B-12 deficiency. He noted that two of the seven reversible cases responded to B-12 replacement. Kassirer and Kopelman (21) described the case of a 62-year-old man who had presented with a four- to six-month history of progressive changes in mental status associated with emotional lability, gait disturbance and visual impairment. They entertained the diagnosis of Alzheimer's disease and began to exclude all 
other reversible causes of dementia. They discovered a low serum B-12 level without hematological manifestations. With vitamin B-12 replacement therapy the patient's mental status was normal in two months, and he could walk without help, followed by improvement in his emotional lability and his visual acuity. Finally, Wieland (22) studied a community of 86 elderly patients and found 5 residents with low serum B- 12 despite being non-anemic. One of these patients carried the diagnosis of dementia. Dramatic clinical improvement was noted in this patient with B-12 therapy.

\section{DISCUSSION}

The evidence that B-12 deficiency is associated with depression, organic psychosis and the aforementioned childhood manifestations lends credence to consideration of obtaining B-12 levels in patients who present with these problems. Evans et al (23), after having two patients with organic psychosis respond to B-12 therapy, stated that “... psychiatric manifestations may be the first symptoms of vitamin B-12 deficiency and thus antedate anemia and spinal cord disease." Because of this, they recommended consideration of B-12 deficiency and serum B-12 determinations in all patients with organic psychiatric symptoms. Hector and Burton (5), who stated that obtaining a serum B-12 level in demented patients was unjustified, also stated that a B-12 level was currently part of the work-up if there was a delirium associated with the dementia. Arguably, in patients over 65 with depression or a psychotic disturbance, a serum B-12 level should become a standard laboratory procedure.

This review found four cases of dementia that were reversible with vitamin B-12 therapy. A much higher number of demented patients had B-12 deficiency, but replacement therapy did not have any effect on the reversal of their dementia. It should also be mentioned that long-term follow-up of the four reversible cases was not addressed in these studies. Larson and Reifler (24), along with Karnaze and Carmel (19), pointed out that without adequate follow-up, it would be difficult to determine whether or not the B-12 deficiency caused the dementia or vice-versa.

It is difficult to disagree with Hector and Burton (5), who stated, ". . . those who contend that vitamin B-12 deficiency causes dementia face the inertia of an impressive amount of clinical work that fails to support that association." To do so, one must take the view that B-12 deficiency causes dementia by a slow process which becomes irreversible after a certain stage in this process is reached.

Thompson and Freedman (16) discuss such a theory based on a model presented by Herbert and Herzlich, who tried to explain B-12 deficiency and its effects on the brain and the nervous system. They proposed four stages of B-12 deficiency: negative B-12 balance, B-12 depletion, B-12-deficient erythropoiesis and B-12 deficiency anemia. Only during the final stage does the patient become anemic and develop an elevated MCV. Thompson and Freedman felt that the most important question was at what stage myelin damage occurred. It seems there is significant doubt still remaining about the association between B-12 deficiency and dementia. Since the time of irreversible myelin damage is not known, it would make sense to try to 
prevent this from happening, possibly preventing a dementia that would be irreversible once it was discovered.

It is impossible to estimate the incidence of vitamin B-12 deficiency with respect to its association with the aforementioned illnesses. Nonetheless, it makes intuitive sense to consider vitamin B-12 deficiency in the normal work-up for any of the clinical entities mentioned in this review. A more important question may lie in the prevention of these illnesses by screening people over age 65 on routine physical exams. A vitamin B-12 level costs approximately $\$ 20.00$. If $10 \%$ of those over 65 will develop vitamin B-12 deficiency (1), then this subset of the population is at risk to develop the aforementioned clinical entities. Considering that a patient with dementia will incur thousands of dollars in medical bills, experience loss of quality of life and stress family members by the amount of care required, screening the population over age 65 appears to be cost effective.

\section{CONCLUSION}

A review of the psychiatric manifestations associated with B-12 deficiency has been discussed. Taking into account the available data, it is advocated that consideration be given to B-12 deficiency as an etiological factor in some cases of depression, organic psychosis in adults, and certain childhood disorders. Also, screening of individuals on routine physical exam at age 65 for B-12 deficiency was advocated as a measure to prevent organic psychoses, depression and dementia (reversible and irreversible) from developing.

\section{ACKNOWLEDGEMENTS}

The authors would like to acknowledge the technical assistance of Tag Heister, University of Kentucky Department of Psychiatry librarian; and Virginia Lynn Gift and Debbie Howard, University of Kentucky Department of Psychiatry word processors.

\section{REFERENCES}

1. Carrethers M: Diagnosing vitamin B-12 deficiency, a common geriatric disorder. Geriatrics 43(3):89-112, 1988

2. Hobbs J, Rodriguez AR: Megaloblastic anemia. AFP 22(6):128-136, 1980

3. Richmond J, Davidson S: Subacute combined degeneration of the spinal cord in nonAddisonian megablastic anemia. Quarterly Journal of Medicine 27:517-531, 1958

4. Moss R, D'Amico S, Maletta G: Mental dysfunction as a sign of organic illness in the elderly. Geriatrics 42(12):35-42, 1987

5. Hector M, Burton JR: What are the psychiatric manifestations of vitamin B-12 deficiency? JAGS 36:1105-1112, 1988

6. Lindenbaum J, Healton EB, Savage DG, Brust JC, Garrett TJ, Podell ER, Marcell PD, Stabler SP, Allen RH: Neuropsychiatric disorders caused by cobalamin deficiency in the 
absence of anemia or macrocytosis. The New England Journal of Medicine 318(26):17201728,1988

7. Levitt AJ, Joffe RT: Vitamin B-12 in psychotic depression. British Journal of Psychiatry $153: 266-267,1988$

8. Levitt AJ, Joffe RT: Folate, B-12, and life course of depressive illness. Biological Psychiatry 25:867-872, 1989

9. Heap BJ, Mumford JD: Chronic giardiasis with vitamin B-12 and folate deficiency presenting with psychiatric symptoms. Journal of the Royal Army Medical Corps 135:2526, 1989

10. Phillips SL, Kahaner KP: An unusual presentation of vitàmin B-12 deficiency. American Journal of Psychiatry 145(4):529, 1988

11. Lassen E, Ewald H: Acute organic psychosis caused by thyrotoxicosis and vitamin B-12 deficiency: Case report. Journal of Clinical Psychiatry 46(3):106-107, 1985

12. Garewal G, Narang A, Das KC: Infantile tremor syndrome: A vitamin B-12 deficiency syndrome in infants. Journal of Tropical Pediatrics 34:174-178, 1988

13. Sadowitz PD, Livingston A, Cavanaugh RM: Developmental regression as an early manifestation of vitamin B-12 deficiency. Clinical Pediatrics 25(7):369-371, 1986

14. Cartlidge PHT, Curnock DA: Specific malabsorption of vitamin B-12 in Down's syndrome. Archives of Disease in Childhood 61 (5):514-515, 1986

15. Hermesh H, Weizman A, Shahar A, Munitz H: Vitamin B-12 and folic acid levels in obsessive-compulsive disorder. Acta Psychiatrica Scandinavica 78:8-10

16. Thompson WG, Freedman ML: Vitamin B-12 and geriatrics: Unanswered questions. Acta Haematologica 82:169-174, 1989

17. Rawlinson F, Eagles JM: Dietary vitamin B-12 deficiency (letter). British Journal of Psychiatry, 145:671, 1984

18. Abalan F, Delile JM: B-12 deficiency in presenile dementia. Biological Psychiatry 20:12471251,1985

19. Karnaze DS, Carmel R: Low serum cobalamin levels in primary degenerative dementia. Archives of Internal Medicine 147:429-431, 1987

20. Renvoize EB, Gaskell RK, Klar HM: Results of investigations in 150 demented patients consecutively admitted to a psychiatric hospital. British Journal of Psychiatry 147:204-205, 1985

21. Kassirer JP, Kopelman RI: Searching for a pony. Hospital Practice 23(11):17-19, 1988

22. Wieland RG: Vitamin B-12 deficiency in nonanemic elderly. JAGS 34:618-619, 1986

23. Evans DL, Edelsohn GA, Golden RN: Organic psychosis without anemia or spinal cord symptoms in patients with vitamin B-12 deficiency. American Journal of Psychiatry $140(2): 218-221,1983$

24. Larson EB, Riefler BV: Response by Larson and Reifler. JAGS 35(5):475, 1987 